\title{
Design and delivery of an innovative speech pathology service-learning program for primary school children in Far West NSW, Australia
}

\section{Sue Kirbya,b,e, David Lyle ${ }^{b}$, Debra Jones ${ }^{b}$, Claire Brunero ${ }^{b}$, Alison Purcellc and Pascale Dettwillerd}

a Centre for Primary Health Care and Equity, UNSW Sydney, Australia

b Broken Hill University Department of Rural Health, University of Sydney, NSW, Australia

c Faculty of Health Sciences, University of Sydney, NSW, Australia

d Port Lincoln Hospital and Health Service, South Australia

e Corresponding author: s.kirby@unsw.edu.au

\section{Article history}

Publication date: September 2018

Citation: Kirby S, Lyle D, Jones D, Brunero C, Purcell A, Dettwiller P. Design and delivery of an innovative speech pathology service-learning program for primary school children in Far West NSW, Australia. Public Health Res Pract. 2018;28(3):e28231806. https://doi.org/10.17061/ phrp28231806

\section{Key points}

- Kindergarten children in the Broken Hill region of New South Wales, Australia, have more learning deficits than children in urban areas

- Access to specialist early childhood communication services in the region is reduced because of chronic rural workforce shortages

- Kindergarten children with unresolved communication deficits do poorly for the rest of their school and adult lives

- Tertiary speech pathology students on clinical placement provided screening, assessment and therapy for kindergarten children in Broken Hill, under the supervision of a local academic, and resolved communication problems in about onequarter of the children treated

\section{Abstract}

Background: Children growing up in Australian rural communities have more communication impairments than their urban counterparts. Communication impairments, if left unresolved in school starters, lead to long-term learning and behavioural problems. Rural communities are disadvantaged by a scarcity of health professionals.

Methods: Supervised speech pathology students on rural clinical placement provided speech, language and communication screening, assessment and therapy to children starting kindergarten in Broken Hill, New South Wales, Australia. The students collected service outcome data for children in the program.

Results: Analysis of the outcome data demonstrated improvements in communication impairments for approximately one-quarter of the children.

Conclusion: The service-learning program used in this study is designed to facilitate implementation in other locations. The model resulted in some improvement in communication impairments. It has the potential to revolutionise undergraduate student learning placements, as well as address the chronic health professional shortage in rural Australia. 


\section{Introduction}

Residents of rural and remote Australia have poorer access to health services and experience poorer health outcomes than their metropolitan counterparts. ${ }^{1}$ Since the 1990s, policy responses focused on providing financial incentives to attract and retain health professionals in these locations have largely been restricted to medical practitioners. ${ }^{2}$ There is growing recognition that further educational innovations are needed to address rural and remote health workforce shortages. ${ }^{3-5}$ The University Departments of Rural Health Program is one of several Australian Government initiatives in tertiary education designed to strengthen and sustain rural and remote healthcare. This includes providing opportunities for students to deliver clinical care, under supervision, to patients with high health needs and poor access to services, in student-led clinics or with students assisting. In student-led clinics, or service-learning, the student provides services under supervision. In contrast, in more traditional clinical placements, students work with health professionals and learn by 'shadowing' them during practice. . $^{6}$

Broken Hill is a socio-economically disadvantaged community in Far West New South Wales (NSW) ${ }^{8}$, Australia. Australian 2016 Census data show that the proportion of Aboriginal people living in Broken Hill is 8.5\% compared with $5.2 \%$ across NSW. ${ }^{8}$ The Broken Hill community has limited access to allied health services, including paediatric speech pathology. ${ }^{9}$ This service deficit is evidenced by the high rate of speech, language and communication delays experienced by Far West NSW primary school children, compared with the NSW average. ${ }^{10,11}$ The 2015 Australian Early Development Census (AEDC) indicates that there are a substantially greater than average number of children in the vulnerable and very vulnerable range for learning deficits in Broken Hill schools. ${ }^{12}$ The reported prevalence of communication delays in Broken Hill primary schools ranges between $13 \%$ and $28.6 \% .{ }^{6}$ If unresolved, speech, language and communication delays can lead to difficulties in learning, literacy, writing and socialisation. These challenges can have long-term implications for the life outcomes of children. Failure to address these delays in childhood can increase the likelihood of later-life contact with juvenile and adult criminal justice systems..$^{9,13-15}$ The Australian Institute of Health and Welfare states that "children who enter school not yet ready for school-based learning have lower levels of academic achievement, and are at an increased risk of teenage parenthood, mental health problems, committing criminal activity and poorer employment outcomes". ${ }^{16}$ Identifying and treating delays in the early years can mitigate these poorer life outcomes. ${ }^{11,17,18}$

In 2009, the Broken Hill University Department of Rural Health (BHUDRH) established a student-led speech pathology clinic in local primary schools in partnership with school education, the local health service and a metropolitan-based faculty of health sciences. The service was developed in response to concerns expressed by primary school principals about the high proportion of children entering school with communication impairments $6,10,19,20$ and the lack of access to allied health services, in this case qualified speech pathologists. ${ }^{9}$ The service-learning program aimed to: 1) support early identification and treatment of speech, language and communication delays in young children; 2) improve the educational, social and health outcomes of children experiencing these delays; 3) facilitate communityengaged learning experiences and work-readiness for speech pathology students; and 4) promote rural and remote practice and primary health care approaches to service provision. The program aligned clinical placements for final-year speech pathology students with provision of services in primary schools across four school terms, under the supervision of a qualified speech pathology academic at the BHUDRH. The program is considered innovative because the service-learning model, although embraced in the US ${ }^{21,22}$, is relatively rare in Australia. ${ }^{20}$ Barriers to rural clinical placements include a shortage of allied health placements, adequacy of supervision, isolation from other university students and learning resources, and lack of placement coordination. ${ }^{23}$ Study findings reported by Jones et al. ${ }^{20}$ indicate that student learning outcomes in this servicelearning classroom-based model may be equal to, if not greater than, those in metropolitan and traditional hospital settings.

The research question is: does the provision of a service-learning model of care improve communication outcomes in children? There is no firm evidence for the hypothesised improvements in communication skills and educational outcomes for school pupils as a result of the service-learning program. This paper describes the design and delivery processes of the Broken Hill speech pathology student-led clinics and reports the service impact of the program. Partnership formation and program development are described in greater detail elsewhere. ${ }^{20}$

\section{Methods}

The service-learning program serves a dual purpose of providing learning opportunities for speech pathology students and school-based services for children that would not otherwise be available. The clinic program was designed to: 1) deliver screening services to identify children starting primary school with mild to moderate delays and those with severe, complex problems; 2) plan and deliver treatment for children with mild to moderate delays (including individual, small group and class-based services); and 3) make referrals to the local health service for children with complex needs for more comprehensive assessment and treatment. Children entering 
kindergarten were recruited annually and could access the service for up to 12 months until the next intake of primary school children. After 12 months, children with ongoing needs were either referred to the local speech pathology service (if severe) or given communication goals and, if suitable, home-based treatment plans.

The detailed service design features described in this paper were provided by co-authors who have developed and continue to work in the service-learning program at the BHUDRH (DJ and CB). All seven Broken Hill primary schools were included in the program. This evaluation is an analysis of the data collected by speech pathology students about the children in the schools in 2014. The program also provides an outreach service to two remote communities not included in this study.

Service activity and outcomes data were collected by the speech pathology students. Data were entered into a database used to manage and monitor speech pathology services for individual children in all Broken Hill primary schools. The speech pathology students recorded data in their notes on key clinical assessments, management decisions and treatments for each child during the placement. Student notes formed medicolegal documentation. Speech, language and communication domains of semantics, comprehension, expressive language and phonological awareness were assessed using the Erin Wilkins Screen of Articulation ${ }^{24}$ and the Screen of Communication Skills. ${ }^{25}$ Children's scores were classified as 'below average', 'average range' or 'above average' based on age-specific normative values. Because of the design of the dataset, client-specific data could be extracted for individual sessions but not other treatment modalities.

To answer the research question of whether the service-learning program improved communication skills in children, proxy outcome measures were applied. At discharge from the program, children were classified in terms of these outcomes: 1) the child reached age-appropriate standard; 2) the child was given communication goals to deal with residual problems and, if suitable, a program supported by teachers/caregivers/ parents; and 3) the child was in need of ongoing service provision from community-based or hospital speech pathologists. All client records were reviewed by the supervising academic speech pathologist.

The data were imported into SPSS (Chicago: IBM; version 24) for analysis. Human ethics approval was given by the Human Research Ethics Committee of the University of Sydney (2015/754), the State Education Research Approval Process (SERAP) of the NSW Department of Education and Communities (SERAP 2015451), and the Aboriginal Health \& Medical Research Council Human Ethics Committee.

\section{Results}

\section{Student-led clinics}

Teachers referred children to the student-led clinics for screening on the basis of demonstrated classroom difficulty or because of concerns expressed by parents or caregivers. Screening sessions were conducted outside the classroom setting. The schools obtained parental consent, and participation rates were reported to be very high. ${ }^{20}$ The severity of each child's communication difficulty was graded as either mild, moderate or severe based on the screening tools (Erin Wilkins Screen of Articulation and the Screen of Communication Skills), additional clinical information, and parental and/or teacher feedback (Table 1). Therapy included one or more treatment modalities: class-based, small groups, individual sessions outside the classroom and home programs. If acceptable to parents and caregivers, home programs were given to some children to supplement school-based activities.

Screening of children began in term 2, allowing time for teachers and parents to identify possible communication problems in children during term 1. Parents could refer their child to teachers if they had concerns. Although there was no specific training for teachers, all teachers recognised communication deficits in children through classroom behaviour. Longer-term involvement in the program helped teachers to identify deficits. If children were already being seen by a speech pathologist, an agreement about school-based services was arranged with the service provider. However, the availability of speech pathology services in Broken Hill is limited.

Each school term, a new group of six speech pathology students provided services for 5-7 weeks. For each child, they provided screening and assessments, and made plans for treatment if indicated. Assessment after screening confirmed the screening findings and indicated the appropriate therapy. Screening sessions were arranged to fit with school curriculum requirements and children's attendance at school, to minimise waiting times. At the end of the 12-month program, in term 1 of the following year, children were formally discharged from the program either: 1) having reached age-appropriate standard; 2) with a 'home' program and communication goals supported by teachers/caregivers/parents; or 3) with a referral for ongoing service provision from community-based or hospital speech pathologists. Each new cohort of speech pathology students was informed by handover notes from the previous student group, and continued to screen, assess and treat children during the program cycle. 
Table 1. Assessment criteria for allocation of therapy, Broken Hill student-led speech pathology clinic

\begin{tabular}{|c|c|c|}
\hline $\begin{array}{l}\text { Severity of } \\
\text { delay }\end{array}$ & Criteria & Therapy \\
\hline Mild & $\begin{array}{l}\text { - Average score achieved in one subtest of Screen of } \\
\text { Communication Skills, but pupil demonstrates specific } \\
\text { delay as identified by speech pathology students or } \\
\text { informed during feedback from caregiver/teacher } \\
\text { - Below average in one subtest of the Screen of } \\
\text { Communication Skills } \\
\text { - Fails to present with a speech sound expected to } \\
\text { have developed within } 6 \text { months of their current age }\end{array}$ & $\begin{array}{l}\text { - Participate in group and class-based therapy for } \\
\text { language or phonological awareness goals } \\
\text { - Participate in individual sessions to elicit speech } \\
\text { sound then offer home program to caregivers to } \\
\text { continue therapy at home, if required } \\
\text { - Pupil offered a review and updated home program } \\
\text { in the next term the service is offered at that school }\end{array}$ \\
\hline Moderate & $\begin{array}{l}\text { - Below average in one or more subtest of the Screen } \\
\text { of Communication Skills } \\
\text { - Fails to present with multiple speech sounds } \\
\text { expected to have developed within 6-12 months of } \\
\text { their current age } \\
\text { - Presents with difficulties in more than one domain } \\
\text { (speech sounds, language and phonological } \\
\text { awareness) }\end{array}$ & $\begin{array}{l}\text { - Individual therapy included in group or class-based } \\
\text { therapy targeting language and/or phonological } \\
\text { awareness goals } \\
\text { - Home program distributed and training offered to } \\
\text { caregivers who accept } \\
\text { - School program distributed and training offered to } \\
\text { student learning and support officer where school } \\
\text { schedules this staff member to deliver school } \\
\text { program regularly }\end{array}$ \\
\hline $\begin{array}{l}\text { Severe } \\
\text { (complex) }\end{array}$ & $\begin{array}{l}\text { - Below average in one or more subtest of the Screen } \\
\text { of Communication Skills } \\
\text { - Fails to present with multiple speech sounds } \\
\text { expected to have developed within 12-24 months of } \\
\text { their current age } \\
\text { - Presents with difficulties in more than one domain } \\
\text { (speech sounds, language and phonological } \\
\text { awareness) }\end{array}$ & $\begin{array}{l}\text { - Referral to speech pathologist at Broken Hill Health } \\
\text { Service if not already currently known to that service } \\
\text { - shared care model } \\
\text { - } \quad \text { Individual therapy (multiple sessions a week) } \\
\text { - Home program and training offered to caregivers } \\
\text { - } \text { - Scho accept } \\
\text { learning and support officer where school } \\
\text { schedules this staff member to deliver school } \\
\text { program regularly }\end{array}$ \\
\hline
\end{tabular}

Student activities were supervised by the BHUDRH speech pathology academic in close liaison with teachers, student learning and support officers, and school principals to ensure the program fitted with the smooth running of the school curriculum. Student supervision included individual and group face-to-face sessions with the academic supervisor at the BHUDRH and teleconferencing with the academic at the student's university when necessary. Students were usually in the final year of their course.

\section{Service activity and outcomes}

In 2014, 122 children who began primary school in Broken Hill were referred for screening - 55\% of the estimated primary school intake of 220 children that year. Children were screened individually in a room at the school outside the classroom.

At screening, most children had delay in one area (speech 34\%, language 17\% and phonological awareness 5\%) and $44 \%$ had delay in multiple areas (Table 2). After 1 year's therapy, 21 (17\%) of those screened had reached an age-appropriate standard in speech, language and communication skills and required no further action; 57 (48\%) had a mild delay/disorder; $31(25 \%)$ had a moderate delay/disorder; and 12 (10\%) had a severe delay/disorder. Of the 101 children needing further action, 71 had deficits in speech, 59 in language and 29 in phonological awareness. Most (82\%) children with delay in one area had a mild problem compared with only $25 \%$ of children with multiple problems $\left(\chi^{2} 33.5\right.$, df 2 , $p<0.001$ ) (Table 2).

The average caseload per speech pathology student ranged from nine to 11 children across the school terms. There were cohorts of six speech pathology students per term. Individual therapy was offered to 70 children and the other 31 children (28 with mild delay) had access to one or more of group therapy, class-based therapy or home/school programs. The mean number of individual sessions increased with the severity of the condition: 3.3, 6.2 and 7.9 sessions on average for children with mild, moderate and severe delay, respectively ( $F 6.803$, df 2, $p=0.002)$. Only three of the 70 children offered individual sessions failed to attend one or more sessions, a rate of $4 \%$.

At the end of the program cycle of one year's therapy, 24 children (24\%) were discharged having reached age-appropriate skills, 56 (55\%) were given communication goals to address residual problems and $12(12 \%)$ were referred for ongoing care from communitybased or hospital speech pathologists (Table 3). There were no statistically significant differences in treatment 
Table 2. Communication problems identified at the student-led speech pathology clinics in Broken Hill, 2014

\begin{tabular}{|c|c|c|c|c|c|}
\hline \multirow[b]{2}{*}{ Severity of delay } & \multicolumn{4}{|c|}{ Communication impairment } & \multirow[b]{2}{*}{ Total } \\
\hline & Speech, $n(\%)$ & Language, $n(\%)$ & $\begin{array}{c}\text { Phonological } \\
\text { awareness, } n(\%)\end{array}$ & Multiple areas, $n(\%)$ & \\
\hline Mild & $31(91)$ & $11(65)$ & $4(80)$ & $11(25)$ & 57 \\
\hline Moderate & $1(3)$ & $4(24)$ & $1(20)$ & $25(57)$ & 31 \\
\hline Severe & $2(6)$ & $2(12)$ & $0(0)$ & $8(18)$ & 12 \\
\hline Total & 34 & 17 & 5 & 44 & 100 \\
\hline
\end{tabular}

Note: Missing data $=1$

Table 3. Treatment outcomes for children attending the student-led speech pathology clinics in Broken Hill, 2014

\begin{tabular}{lccccc}
\hline & \multicolumn{5}{c}{ Discharge from program } \\
\cline { 2 - 5 } Severity of delay & $\begin{array}{c}\text { No further treatment, } \\
n(\%)\end{array}$ & $\begin{array}{c}\text { Discharged with } \\
\text { goals, } n(\%)\end{array}$ & $\begin{array}{c}\text { Speech pathologist } \\
\text { referral, } n(\%)\end{array}$ & Missing data, $n$ & Total \\
\hline Mild & $17(71)$ & $34(61)$ & $1(8)$ & 6 & 38 \\
Moderate & $6(25)$ & $22(39)$ & 0 & 3 & 31 \\
Severe & $1(4)$ & 0 & $11(92)$ & 0 & $\mathbf{9}$ \\
Total & $\mathbf{2 4}$ & $\mathbf{5 6}$ & $\mathbf{1 2}$ & $\mathbf{9}$ & $\mathbf{1 0 1}$
\end{tabular}

outcomes for the service-learning program between children with mild and moderate delays/disorders. Only one of the 12 children with a severe delay/disorder was discharged having reached an age-appropriate level; the rest required ongoing access to speech pathology interventions. Of the children offered treatment, $29 \%$ were of Aboriginal and Torres Strait Islander background. The severity of the speech or language delays did not differ statistically between Aboriginal and non-Aboriginal children (54\% and 58\% presented with mild delay, respectively), but significantly more Aboriginal children were discharged with set goals to work on with parents and teachers (88\% vs 67\%, $\chi^{2} 4.439$, df 1 , $p<0.05)$.

\section{Discussion}

There is strong evidence for the positive impact of speech pathology services on communication outcomes in kindergarten children. ${ }^{17}$ This speech pathology service-learning program has proved to be an effective model for delivering services to primary school children in Broken Hill since 2009. The positive features of the program, which testify to the effectiveness of the model, including acceptability and parental support, have been reported by Jones et al. in another study. ${ }^{19}$ All primary schools participated in the program and there were high satisfaction levels with the responsiveness of the service model. Parental support was very high - up to $100 \%$ in some schools - and scheduled therapy was delivered in most instances. ${ }^{26}$ The low 'failure-to-attend' rate for individual sessions provides confirmatory evidence of the acceptability of the program. On balance, the model is acceptable and accessible in the context of limited service availability and socio-economic disadvantage. The limited availability of other alternative speech pathology services in Broken Hill means it is unlikely that access to other services contributed to improvements in communication outcomes.

In 2014, 101 (46\%) children starting kindergarten in Broken Hill were assessed as having delays in development of speech, language or phonological awareness. The AEDC-reported proportion of children with vulnerability in one or more domains is twice as high in Broken Hill than in NSW as a whole. ${ }^{12}$ Although more sensitive screening instruments provide a more realistic screening measure of the need for paediatric speech pathology services in the community, the choice of the Erin Wilkins Screen of Articulation and the Screen of Communication Skills was based on their availability and acceptability to students.

As reported in a separate study, continuity of care was ensured through handover notes from each group of students to the next cohort, complemented by guidance from the speech pathology academic at the BHUDRH. ${ }^{26}$ Another positive feature of the service model was the integration of the student-led service with existing local allied health services for ongoing care of children referred with complex needs. The service was effective at identifying children with mild and moderate delays as well as finding the smaller number of severe complex cases that were referred (if not already in their care) to hospital services. 
For these children, the students contributed through a shared care model by delivering elements of the therapy plan developed and guided by hospital speech pathologists. The colocation of the service in primary schools allowed for ongoing class-based activities to support children who made progress in communication skills but still needed additional services to overcome residual deficits at the formal completion of the 12-month program.

Most (70\%) children (all severe, 95\% with moderate and $50 \%$ with mild delays) were offered individual therapy sessions. For the remainder, other treatment modalities, namely group and class-based therapy, and home/school programs, were recommended. The average number of individual sessions was relatively low based on current clinical practice norms. This may be an underestimate of the total treatment received because data about other modalities accessed by these children was incomplete and therefore could not be analysed. The possibility that clients could be accessing other services is considered unlikely because of the limited availability of services in Broken Hill.

It is encouraging that about one-quarter of children had their problems resolved. However, the limited clinical data about individual children made it difficult to provide comprehensive assessment of clinical outcomes. It should also be acknowledged that children might have improved without therapy. This study has prompted redesign of the data collected about children accessing the program to provide more complete clinical outcomes data. A similar speech pathology servicelearning program in the remote town of Katherine in the Northern Territory, Australia, has reported on goalsbased measurement of outcomes, which measures the progress of each child against individual targets. It demonstrated a positive impact from service-learning on aggregated goal attainment in primary school children. This was a promising result because a high proportion of Aboriginal children who participated in the study spoke creole and/or an Aboriginal language at home and standard Australian English at school. ${ }^{27}$ In addition, a telehealth speech pathology program delivered in rural NSW has reported positive results using a goals-based approach for measuring pupil speech and language outcomes. In that study, $96 \%$ of children in group therapy met or exceeded their language and phonological awareness goals. ${ }^{28} \mathrm{~A}$ comparison of the relative merits of measuring clinical and service outcomes versus goalsbased approaches would add to our understanding of evaluating program effectiveness.

There are several limitations to this study. For the Broken Hill service model, additional data are needed about the intensity and duration of treatment by all modalities, the goals of therapy and goal attainment to determine whether the program has achieved its full potential for measurable clinical improvement.
Further research should also examine the impact of the program on children's classroom engagement and participation, and learning, as well as on educational outcomes such as basic numeracy and literacy. The low sensitivity of the screening tools may have limited the extent to which false positives were identified. This is a possible limitation. Another limitation is that other confounding factors that may have accounted for improvements in children's communication were not identified.

The provision of service-learning programs involves a complex series of interactions and agreements across the health, tertiary and primary education sectors. The factors that come into play in the transferability and scalability of this service-learning model include: 1) the higher cost of clinical placements per speech pathology student; 2) the source of funding for the service-learning model; 3) the need to negotiate agreements with universities providing students; 4) the schools in which service-learning programs are delivered; and 5) the local health services to which children may be referred. ${ }^{20,28}$

Use of service-learning placements in which undergraduate students provide services under supervision, as an innovative approach to addressing student learning and health workforce shortages, has attracted interest in Australia. ${ }^{29}$ There is a large body of evidence about its positive impact on student learning, including evaluation data from the Broken Hill allied health student-led clinics. ${ }^{30,31}$ However, there is limited information about the impact and outcomes of substantial clinical programs such as this for communities and clients. These findings show that clinically based allied health service-learning programs are feasible and can be sustainable in the Australian setting. The success of these programs is also linked to the community-academic partnerships that underpin the student-led clinic model in schools. ${ }^{32}$ Clinical-based service-learning programs can address gaps in service availability under specific circumstances and deliver acceptable and accessible care while working effectively in collaboration with established services.

\section{Conclusion}

The speech pathology service-learning program in primary schools in Broken Hill is a comprehensive evidence based service designed to meet the dual goals of addressing primary school pupil communication deficits and providing speech pathology students with a fruitful learning experience. The preliminary findings reported here showed improvement in communication impairments to age-appropriate levels in about onequarter of school pupils.

\section{Peer review and provenance}

Externally peer reviewed; not commissioned. 


\section{Competing interests}

None declared.

\section{Author contributions}

SK and CB constructed the database. CB, DJ and DL contributed to the description of the service-learning program. SK and DL analysed, planned and wrote the manuscript. CB, DJ, AP and PD provided expert comments and contributed to the revision of the text

\section{References}

1. Humphreys JS, Wakerman J, Wells R, Kuipers P, Jones JA, Entwistle P. "Beyond workforce": a systemic solution for health service provision in small rural and remote communities. Med J Aust. 2008;188(8):S77-80.

2. Lyle D, Morris J, Garne D, Jones D, Pitt M, Walker T, Weston R. Value adding through regional coordination of rural placements for all health disciplines: the Broken Hill experience. Aust J Rural Health. 2006;14(6):244-8.

3. Lyle D, Klineberg I, Taylor S, Jolly N, Fuller J, Canalese $J$. Harnessing a university to address rural health workforce shortages in Australia. Aust J Rural Health. 2007;15(4):227-33.

4. Smith T, Brown L, Cooper R. A multidisciplinary model of rural allied health clinical-academic practice: a case study. J Allied Health. 2009;38(4):236-41.

5. Australian Rural Health Education Network. Canberra: ARHEN; 2013 [cited 2013 Oct 9]; [about 2 screens]. Available from: www.arhen.org.au

6. Jones D, Grant-Thomson D, Bourne E, Clark P, Beck H, Lyle D. Model for rural and remote speech pathology student placements: using non-traditional sites and partnerships. Aust J Rural Health. 2011;19(1):52-3.

7. Seifer SD. Service-learning: community-campus partnerships for health professions education. Acad Med.1998;73(3):273-7.

8. .idcommunity demographic resources. Melbourne: id Consulting; c. 1997-2018. Broken Hill City community profile; [cited 2018 Feb 7]; [about 7 screens]. Available from: profile.id.com.au/broken-hill/seifa-disadvantage

9. Community Affairs References Committee. Prevalence of different types of speech, language and communication disorders and speech pathology services in Australia. Canberra: Community Affairs References Committee; 2014 [cited 2018 Feb 14]. Available from: www.aph.gov. au/ /media/Committees/Senate/committee/clac_ctte/ speech_pathology/report/report.pdf?la=en

10. Australian Early Developmental Index. Melbourne: AEDC; 2014 [cited 2015 Mar 10]. Available from: www.aedc.gov.au/
11. Glover A, McCormack J, Smith-Tamaray M. Collaboration between teachers and speech and language therapists: services for primary school children with speech, language and communication needs. Child Lang Teach Ther. 2015;31(3):363-82.

12. Australian Early Development Census. Melbourne: AEDC; c.2014-2015. Far West NSW community data explorer; [cited 2018 Feb 7]; [about 3 screens]. Available from: www.aedc.gov.au/data/data-explorer?id=68222

13. National Institute on Deafness and Other Communication Disorders. Maryland (US): NIDCD. Specific language impairment; 2017 [cited 2013 Sept 4]; [about 3 screens]. Available from: www.nidcd.nih.gov/health/voice/pages/ specific-language-impairment.aspx

14. Australian Institute of Criminology. Canberra: AIC; 2017. Snow P, Powell M. Youth (in)justice: oral language competence in early life and risk for engagement in antisocial behaviour in adolescence; 2017 [cited 2018 Feb 14]; [about 13 screens]. Available from: aic.gov.au/ publications/tandi/tandi435

15. Snow $P$, Powell M. Oral language competence in incarcerated young offenders: links with offending severity. Int J Speech Lang Pathol. 2011;13:480-9.

16. Australian Institute of Health and Welfare. National outcome measures for early childhood development: development of an indicator-based reporting framework. Canberra: AlHW; 2011 [cited 2018 Jun 6]. Available from: www.aihw.gov.au/getmedia/4b41f3af-33aa-4ad7-b867fe4f9ef51a6e/12424.pdf.aspx?inline=true

17. Law J, Garrett Z, Nye C. Speech and language therapy interventions for children with primary speech and language delay or disorder. Cochrane Database Syst Rev. 2003;(3):CD004110.

18. Hillier S. Intervention for children with developmental coordination disorder: a systematic review. Int J Allied Health Sci Pract. 2007;5(3)

19. Jones D, Grant-Thomson D, Bourne E, Lyle D. Investing in the future of rural and remote allied health and kids. 11th National Rural Health Conference; 2011 Mar 13-16; Perth, Western Australia.

20. Jones D, Lyle D, Brunero C, McAllister L, Webb T, Riley S. Improving health and education outcomes for children in remote communities: a cross-sector and developmental evaluation approach. Gateways. 2015;8(1):1-22.

21. Jacoby B. Partnerships for service learning. New Directions for Student Services. 1999(87):19-35.

22. Moscovice I, Wellever A, Christianson J, Casey M, Yawn B, Hartley D. Understanding integrated rural health networks. Milbank Q. 1997;75(4):563-88.

23. Spiers MC, Harris M. Challenges to student transition in allied health undergraduate education in the Australian rural and remote context: a synthesis of barriers and enablers. Rural Remote Health. 2015;15(2):3069. 
24. Small Talk Speech and Language Therapy. Sydney: Small Talk; 2015. Wilkins E. Speech and Articulation; 2015 [cited 2015 Jun 1]; [about 2 screens]. Available from: smalltalkspeech.com.au/speech-articulation/

25. James $H$, Turnell A. Screen of Communication Skills (SOCS): Kindergarten \& pre-primary (Speech Pathology Test Collection). Language by Design; 2008.

26. Jones D, McAllister L, Lyle D. Challenging remote community deficit perspectives: an Australian insight into the role of these communities in the design of their health services and the development of their health workforce. International Journal of Practice-based Learning in Health and Social Care. 2016;4(2)

27. Dettwiller P, Maroney T, and Brown L, S.E.L.L. 'Speak easy for learning and living' service-learning program: future and opportunities for our communities. The Lowitja Institute Conference "Identity Knowledge Strength"; 2016 Nov 8-10; Melbourne, Victoria.

28. Stolp E, McGrath J, Davies L. Using telehealth to support students with language and phonological awareness needs. 5th NSW Rural Health and Research Congress; 2016 Nov 9-11; Tweed Heads, NSW.
29. Mason J. Review of Australian Government health workforce programs. Canberra: Australian Government Department of Health; 2013 May 24 [cited 2018 Feb 14]. Available from: www.health.gov.au/internet/main/ publishing.nsf/Content/D26858F4B68834EACA257 BF0001A8DDC/\$File/Review\%20of\%20Health\%20 Workforce\%20programs.pdf

30. Jones D, McAllister L, Lyle D. Stepping out of the shadows: allied health student and academic perceptions of the impact of a service-learning experience on student's work-readiness and employability. Journal of Teaching and Learning for Graduate Employability. 2015;6(1):66-87.

31. Jones D, McAllister L, Lyle D, Interprofessional academic service-learning in rural Australia: exploring the impact on allied health student knowledge, skills, and practice. A qualitative study. International Journal of Practice-Based Learning in Health and Social Care. 2015;3(2):1-16.

32. Kirby S, Held F, Jones D, Lyle D. Growing health partnerships in rural and remote communities: what drives the joint efforts of primary schools and universities in maintaining service learning partnerships? Prim Health Care Res Dev. 2018;10:1-15.

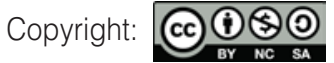

(C) 2018 Kirby et al. This article is licensed under the Creative Commons Attribution-NonCommercial-ShareAlike 4.0 International Licence, which allows others to redistribute, adapt and share this work non-commercially provided they attribute the work and any adapted version of it is distributed under the same Creative Commons licence terms. See: www.creativecommons.org/licenses/by-nc-sa/4.0/ 